\title{
Kultur Sekolah dalam Membentuk Kedisiplinan Siswa di SMA Angkasa Adi Sutjipto Yogyakarta
}

\author{
Anggi Permata Sari, Poerwanti Hadi Pratiwi dan Aris Martiana \\ Pendidikan Sosiologi Universitas Negeri Yogyakarta \\ Email : sarianggi4@gmail.com
}

\begin{abstract}
Abstrak
Penelitian ini mendeskripsikan kultur sekolah dalam membentuk kedisiplinan siswa di SMA Angkasa Adisutjipto. Penelitian menggunakan metode penelitian kualitatif. Informan pada penelitian ini berjumlah 11 orang. Teknik pemilihan informan menggunakan purposive sampling. Pengumpulan data dengan cara observasi, wawancara dan dokumentasi. Validitas data yang digunakan adalah triangulasi sumber. Teknik Analisis data menggunakan analisis model interaktif Miles Huberman yang meliputi pengumpulan data, reduksi data, penyajian data dan penarikan kesimpulan. Hasil penelitian ini menunjukkan bahwa disiplin sebagai kultur utama sekolah karena pendidikan di SMA Angkasa berbasis semi militer yang di bimbing TNI AU secara langsung. Selain itu dari artifak fisik seperti; lokasi sekolah berada komplek AURI, seragam siswa lengkap dengan atribut kedirgantaraan, logo sekolah menunjukan berada dibawah naungan AURI. Pada artifak perilaku menunjukkan hubungan yang harmonis antar warga sekolah, yang terlihat dari pola perilaku penerapan $3 \mathrm{~S}$ (senyum, salam dan sapa). Temuan terakhir yaitu pada nilai dan keyakinan yang dianut warga sekolah, berupa nilai kejujuran, keteladanan, kedisiplinan dan ketertiban.

Kata Kunci: Kultur Sekolah, Disiplin
\end{abstract}

Abstract

This research described school culture in shaping student discipline in Angkasa Adisutjipto High School. The method used in this research was descriptive qualitative means. The informants in this research were 11 people. The informant selection technique uses purposive sampling. Collecting data was conducted by interviews, observation, and documentation. The data validity used in this research was methodological triangulation. This research used Miles and Huberman's model in order to analysed the data; the method consists of data collection, data reduction, data presentation, and drawing conclusion. The results of this research indicate that discipline is the main culture of the school because of education in a semi-military based Space Senior High School guided by the Indonesian Air Force directly. In addition, from physical artifacts such as; the location of the school is in the Air Force complex, student uniforms complete with aerospace attributes, the school logo shows under the auspices of the Air Force. Behavioral artifacts show a harmonious relationship between school members, which can be seen from the behavior pattern of applying the $3 \mathrm{~S}$ (smile, greetings and greetings). The last finding is on the values and beliefs adopted by the school community, in the form of values of honesty, exemplary, discipline and order.

Keywords: School Culture, Discipline

\section{Pendahuluan}

Pada umumnya sekolah yang tertib akan selalu menciptakan proses pembelajaran yang baik, sebaliknya pada sekolah yang tidak tertib kondisinya akan jauh berbeda. Setiap sekolah memiliki keunikan tersendiri, hal ini tercermin dari budaya sekolah (kultur sekolah) dari seluruh anggota masyarakat yang ada di sekolah, baik itu melalui sistem ataupun tradisi yang dilaksanakan dan diwariskan secara turun temurun (Febriyanti, 2015). 
SMA Angkasa Adisutjipto memiliki pendidikan karakter yang baik, SMA ini mengutamakan kedisiplinan yang diwujudkan dalam pembentukan visi sekolah yaitu "Disiplin, Bermutu, Peduli, dan Budaya lingkungan berdasarkan Iman dan Taqwa". Visi inilah yang mendorong dan menjadi tekad bagi seluruh guru dan karyawan serta warga sekolah untuk menciptakan sumber daya manusia yang berkualitas tinggi di setiap kelulusan peserta didik.

Demi lancarnya pendidikan SMA Angkasa Adisutjipto menerapkan tata tertib yang mengarah pada sikap disiplin, SMA ini menyusun aturan tata tertib dengan sistem skore terkait pelanggaran yang dilakukan siswa, hal ini dilakukan berdasar keinginan pihak sekolah dan orang tua siswa untuk menciptakan kondisi sekolah yang tertib dan disiplin, sehingga kegiatan belajar dan mengajar/KBM berjalan lancar. Untuk menciptakan iklim yang kondusif berawal dari upaya pembiasaan diri yang kemudian membentuk budaya sekolah. Pembiasaan yang baik akan menghasilkan budaya yang positif, demikian sebaliknya (Aman, Sudrajat, \& Yuliana, 2018).

SMA Angkasa Adisutjipto dengan sekolah lainnya memiliki kultur yang berbeda. Saat ini belum banyak sekolah yang paham bahwa kultur sekolah yang baik dan positif akan berkontribusi pada kualitas pendidikan di sekolah. Begitu juga dengan siswa di SMA Angkasa Adisutjipto memiliki perbedaan dengan siswa di sekolah lainnya diantaranya, beberapa siswa di SMA Angkasa Adisutjipto Yogyakarta merupakan siswa pindahan yang memiliki masalah disekolah sebelumnya, selain itu siswa di SMA Angkasa Adisutjipto masih kurang memahami tentang pentingnya kedisiplinan selama proses pembelajaran dan tingkat kedisiplinan belajar siswa selama proses pembelajaran kurang terlihat. Untuk itu SMA Angkasa Adisutjipto memberikan kesempatan bagi mereka yang mengalami serangkaian permasalahan dan berkeinginan untuk melanjutkan pendidikan, serta SMA Angkasa Adisutjipto bersedia memberikan pendidikan karakter yang baik dengan mengutamakan kedisiplinan, hal ini menjadi alasan bagi peneliti tertarik untuk mengetahui kultur sekolah dalam membentuk kedisiplinan siswa di SMA Angkasa Adisutjipto.

\section{Metode}

Penelitian ini menggunakan metode penelitian kualitatif dengan pendekatan dekriptif. Lokasi penelitian yang digunakan sebagai obyek penelitian berlokasi di SMA Angkasa Adisutjipto. Sekolah ini berada di jalan Janti Lanud Adisutjipto Yogyakarta, SMA ini berada dikawasan pangkalan udara AURI (Angkatan Udara Republik Indonesia). Alasan memilih SMA Angkasa Adisutjipto Yogyakarta sebagai objek penelitian karena SMA ini merupakan sekolah yang berbasis semi militer yang mengedepankan pendidikan kedisiplinan dan termasuk sekolah yang ter-akreditas $A$. 
Penelitian ini dilaksanakan selama 3 bulan terhitung dari bulan oktober hingga desember 2018. Teknik pemilihan informan dalam penelitian ini menggunakan teknik purposive sampling. Pihak yang mendukung kebijakan tata tertib dan aturan di SMA Angkasa Adisutjipto Yogyakarta. Adapun teknik pengumpulan data dalam penelitian ini dilakukan dengan wawancara, observasi, dan dokumentasi.

\section{Hasil dan Pembahasan}

\section{Disiplin Sebagai Kultur Sekolah Utama}

SMA Angkasa Adisutjipto merupakan satu-satunya SMA yang mengajarkan Aero Modeling dan kedirgantaraan diantara SMA-SMA se-kabupaten sleman. SMA Angkasa berada di bawah Yayasan Ardhaya Garini bekerja sama TNI AU dengan pelindung Komandan Lanud Adisutjipto bersama-sama membentuk siswa kreatif dan disiplin. SMA Angkasa Adisutjipto memiliki pendidikan karakter yang baik, dengan mengutamakan kedisiplinan yang diwujudkan dalam pembentukan visi sekolah yaitu "Disiplin, Bermutu, Peduli, dan Budaya lingkungan berdasarkan iman dan taqwa”.

Nilai kedisiplinan disosialisasikan melalui contoh atau teladan. Memberikan contoh kedisplinan maka perlu adanya konsistensi dari diri yang memberikan contoh, demi terbentuknya karakter bagi siswa maupun warga sekolah lainnya (Sari \& Farida, 2017).

Dalam mendisiplinkan siswa diperlukan penguatan karakter siswa. Penguatan karakter tersebut berupa penguatan lingkungan, pembiasaan, dan pengajaran. SMA Angkasa memiliki strategi dalam mengisi jam yang kosong, di SMA Angkasa tidak ada jam kosong dan peluang tersebut dimanfaatkan dengan memberikan tugas pengganti agar siswa tidak keluar masuk kelas. Pembiasaan seperti ini sangat mendidik dan melatih siswa untuk belajar mandiri. Selain itu contoh yang diberikan menjadi pionir bagi siswa untuk menjadi siswa yang tepat waktu karena melihat guru-guru yang memberikan contoh untuk datang lebih awal. Peneliti menemukan kedisiplinan sebagai kultur sekolah utama yang terlihat dari:

a. SMA Angkasa merupakan sekolah kedirgantaraan dengan mengutamakan Pembentukan karakter peserta didik yang langsung di didik oleh TNI AU.

b. Hubungan yang harmonis diantara warga sekolah dengan menerapkan $3 \mathrm{~S}$ (senyum, salam dan sapa).

c. Apel pagi dilakukan setiap hari di SMA Angkasa Adisutjipto pada pukul 6.30.

d. Tata tertib yang berlaku pada umumnya berisi terkait seragam siswa, kehadiran siswa dalam setiap event, dan peraturan lainnya.

Peraturan dan tata tertib di SMA Angkasa Adisutjipto Yogyakarta disadari oleh siswa dan dianggap membawa siswa kearah yang baik dan positif, dan siswa memiliki kesadaran penuh dalam melaksanakan tata tertib yang ada. 


\section{Artifak Sebagai Kultur Sekolah dalam} Mendukung

Pembentukan

\section{Kedisiplinan Siswa}

a. Artifak Fisik

SMA Angkasa Adisutjipto berada dikawasan pangkalan udara AURI (Angkatan Udara Republik Indonesia) dan jarak nya berseberangan dengan jalan raya, sehingga dari segi keamanan sekolah tersebut sangat aman karena terjaga oleh Angkatan Udara. Selain itu lokasi SMA Angkasa Adisutipto cukup strategis dengan akses kendaraan yang mudah dan aman karena terjaga oleh Angkatan Udara AURI.

Sarana yang terdapat di SMA Angkasa adalah mulai dari taman dan halaman sekolah, ruang bimbingan konseling, gedung sekolah, interior sekolah ketersediaan alat-alat penunjang ekstrakulikuler, laboratorium, kantin sekolah serta tempat ibadah. Sarana transportasi mudah di akses bagi penulis karena jaraknya yang berada di jalan raya, namun untuk ojek dan angkutan umum hanya diperbolehkan berhenti sampai depan pangkalan udara, dan untuk kendaraan pribadi diperbolehkan memasuki kawasan Angkatan udara. SMA Angkasa Adisutjipto berada di kawasan kompleks AURI yang didalamnya memiliki klinik AURI, supermarket dan masjid dengan begitu akses sekolah sangat dekat dengan lingkungan masyarakat.

Logo SMA Angkasa Adisutjipto menggambarkan bahwa SMA Angkasa Adisutjipto merupakan "Sekolah Rintisan Unggulan Angkasa Indonesia" dengan visi yaitu: Terwujudnya Sekolah Angkasa yang unggul dan rujukan dalam menghasilkan abdi yang beragama, berbangsa dan bernegara serta berilmu demi kejayaan Nusantara. Pada logo tercantum tulisan SMA Angkasa Adisutjipto Yogyakarta yaitu sebagai lambang sekolah dan pada bagian bawah terdapat tulisan "Lanud Adisutjipto Yogyakarta" dengan makna bahwa SMA Angkasa berada di lingkungan Militer, dan sekolah tersebut di kelola oleh suatu yayasan TNI AU, yaitu Yayasan Ardhya Garini Pengurus Cabang Lanud Adi Sutjipto.

Selain itu TNI AU merupakan salah satu tenaga pendidik pendukung guna membentuk karakter dan kedisiplinan siswa, sehingga siswa-siswi yang ada di SMA Angkasa tahu pasti bahwa mereka berada di kawasan landasan AU Adisutjipto dan budaya disiplin siswa terbentuk mereka berusaha untuk mematuhi aturan yang ada terkait dengan kebijakan yang tertulis di dalam peraturan dan tata tertib yang berlaku disekolah.

b. Artifak Perilaku 
SMA Angkasa mengajarkan agar siswa selalu menerapkan $3 \mathrm{~S}$ (senyum, salam dan sapa) baik antar siswa dengan kakak kelas, antar siswa dengan guru maupun antar siswa dengan petugas militer AU. Dari segi penampilan siswa setiap harinya terlihat rapi dan bersih, karena di pagi hari mulai pukul 5.30 petugas militer AU berada di depan gerbang untuk mengecek kerapian dan kedisiplinan kehadiran siswa.

Perilaku tersebut diajarkan guna membentuk karakter disiplin siswa karena merupakan bagian dari kultur sekolah yang dianut SMA Angkasa dan sesuai dengan visi-misi sekolah salah satu nya yaitu membentuk kedisiplinan siswa. Dengan melakukan pembiasaaan pembiasaan tersebut dalam kehidupan sehari-hari maka karakter siswa akan lebih mudah dibentuk untuk menjadi siswa yang disiplin.

Temuan tersebut dikuatkan dengan temuan penelitian lain sebagai berikut: "Internalisasi dan penekanan nilai-nilai karakter. Hal ini bertujuan untuk menjadikan peserta didik memiliki keimanan dan ketaqwaan yang kuat, cinta tanah air, memiliki empati yang tinggi, serta menjadi teladan yang baik bagi teman dan orang di sekitarnya. Internalisasi nilai-nilai karakter dilakukan baik dalam pembelajaran seluruh mata pelajaran, maupun dalam kebiasaan sehari-hari" (Susilo, 2016).

Menjaga kebersihan lingkungan, meski kebersihan lingkungan menjadi tugas utama petugas kebersihan. Namun sebagai sekolah adiwiyata, semua warga sekolah mempunyai kewajiban untuk menjaga kebersihan lingkungan sekolah. Lingkungan SMA Angkasa memiliki kegiatan cinta lingkungan yang diadakan rutin setiap hari selasa dengan maksud menjaga lingkungan yang nyaman dan bersih, dengan begitu semua warga sekolah diberikan tanggungjawab untuk menjaga sarana dan prasarana sekolah.

3. Nilai-nilai yang diyakini dan di Implementasikan di SMA Angkasa

Sikap dan keyakinan yang dimiliki warga sekolah berkaitan dengan kehidupan sekolah yang bersangkutan. Nilai-nilai ini tidak dapat dilihat secara langsung tetapi dapat ditemukan dalam wujud, visi-misi, motto, prinsip-prinsip dan semangat yang ada (Zamroni, 2011).

Aspek penilaian yang diyakini dan di implementasikan di SMA Angkasa Adisutjipto Yogyakarta:

a. Kebanggaan terhadap sekolah

b. Perwujudan visi dan misi sekolah

c. Penghargaan sekolah atas prestasi warga sekolah

d. Kompetisi siswa dalam meraih prestasi

e. Slogan-slogan yang ada disekolah

f. Penerapan nilai yang ada disekolah 
Pertama peneliti menemukan data terkait kenyamanan dari warga sekolah yang dapat ditunjukkan dari kebanggaan warga sekolah terhadap sekolah SMA Angkasa Adisutjipto. Menjadi bagian dari SMA Angkasa Adisutjipto merupakan sebuah kebanggaan bagi informan, terutama karena lingkungan sekolah yang bagus dan kondusif karena lingkungan sekolah berada dibawah naungan TNI AU dan rasa bangga tersebut berdasarkan keinginan ibu SR untuk membesarkan nama SMA Angkasa yang merupakan bagian dari keluarga TNI AU.

Rasa bangga warga sekolah terhadap SMA Angkasa terlihat jelas, secara garis besar rasa tersebut dirasakan oleh warga sekolah, baik oleh guru maupun siswa karena merupakan bagian dari sekolah tersebut dan mengakui keunggulan dari SMA Angkasa yaitu pada peraturan yang berlaku dan menjunjung tinggi perilaku disiplin.

Kedua, nilai dan keyakinan berupa usaha untuk mewujudkan visi dan misi sekolah. Pencapaian visi dan misi yang ditetapkan di sekolah tentunya membutuhkan proses dan butuh usaha dari setiap warga sekolah terutama siswa sebagai subyek dalam kegiatan-kegiatan sekolah. Siswa SMA Angkasa Adisutjipto mengupayakan untuk mewujudkan visi dan misi sekolah yaitu dengan cara mematuhi peraturan yang berlaku di sekolah, dengan mengikuti kegiatan-kegiatan upacara yang diselenggarakan di sekolah serta menjadi siswa yang miliki prestasi.
Ketiga, keyakinan melalui pemberian penghargaan yang diberikan sekolah untuk warga sekolah yang berprestasi. Penghargaan diberikan kepada murid yang berprestasi di bidang akademik maupun non-akademik, Reward yang diberikan berbeda-beda sesuai dengan kemampuan sekolah dan pemberian reward terhadap siswa guna sebagai bentuk penghargaan atas prestasi siswa dan sekaligus sebagai motivasi agar siswa dapat mempertahankan dan meningkatkan prestasi nya serta menjadi motivasi juga untuk siswa lainnya agar semangat dalam meraih prestasi.

Keempat, keyakinan melalui kompetisi siswa dalam meraih prestasi. Semangat berprestasi siswa dapat dilihat dari peran guru yang selalu memberikan moivasi dalam berprestasi untuk memunculkan kemauan siswa untuk memiliki prestasi baik didalam sekolah maupun di luar sekolah.

Kelima, nilai dan keyakinan di SMA Angkasa Adisutjipto dilihat peneliti melalui slogan-slogan, tatib maupun visi dan misi yang dipasang di sekolah. Disetiap sudut sekolah terpasang slogan-slogan, visi misi maupun tata tertib. Secara garis besar siswa SMA Angkasa merupakan siswa yang disiplin dari segi waktu, patuh pada aturan yang berlaku serta menerapkan $3 \mathrm{~S}$ yang merupakan singkatan dari senyum, sapa, salam. Siswa dan siswi SMA Angkasa mengakui kepatuhan mereka terhadap adanya slogan yang ditempel di setiap sudut sekolah. Kepatuhan mereka 
terhadap slogan juga diperhatikan oleh pihak TNI AU dengan begitu siswa dan siswi menganggap kepatuhan terhadap visi-misi, tata tertib maupun slogan merupakan sebuah keharusan dan telah menjadi sebuah kebiasaan bagi mereka.

Yang terakhir merupakan penerapan nilai-nilai yang ada disekolah yang dilakukan oleh seluruh warga sekolah. Penerapan nilai-nilai yang ada di sekolah yaitu dengan membentuk mengajarkan nilai kejujuran, keteladanan, kedisiplinan dan ketertiban, nilai-nilai tersebut dianggap penting dan diterapkan melalui sikap serta perilaku sehari-hari.

Budaya sekolah yang positif dan produktif mampu memberikan pengalaman baik, bagi pertumbuhan siswa secara utuh, tidak saja pada aspek kognitif pada prakteknya juga melainkan pada aspek psikomotorik dan afektifnya yaitu dengan mengajarkan nilai kejujuran, keteladanan, kedisiplinan dan ketertiban serta kepedulian. Budaya sekolah dapat dikatakan sebagai kualitas kehidupan sekolah yang tumbuh berkembang berdasarkan spirit dan nilai-nilai yang dimiliki serta perilaku yang dianut warga sekolah (Benaziria \& Murdiono, 2019). Budaya sekolah tercermin dalam hubungan antar warga sekolah baik pada saat bekerja, kegiatan belajar-mengajar, maupun pada nilai-nilai yang terlihat saat berkomunikasi satu sama lain.

Nilai-nilai kejujuran dimiliki oleh siswa SMA Angkasa, pada prakteknya nilai tersebut dibentuk dari sikap disiplin siswa yang tercermin dalam karakter siswa. Dalam kenyataan yang ada pada saat ini dalam system pendidikan, sekolah meupakan agen yang menjadikan guru untuk mengawasi dan membentuk kepribadian siswa. Sesungguhnya peran guru dalam membangun tradisi kejujuran akadmik terdiri pada tiga aspek, pertama; membangun kejujuran harus dimulai dari diri sendiri sebagai seorang guru, yakni antara perkataan, perbuatan dan tindakan harus sesuai dengan norma-norma yang berlaku. Kedua; sebagai seorang guru yang tugas utamanya adalah mendidik, melatih, mengarahkan, menilai dan mengevaluasi peserta didik, maka guru mempunyai kewajiban untuk membentuk karakter anak didiknya untuk memiliki sikap disiplin, jujur, mandiri, demokratis dan bertanggungjawab. Ketiga; guru sebagai akademik juga mempunyai tanggungjawab untuk membesarkan lembaga (sekolah), maka guru dalam hal ini harus mampu membangun dana memberi keteladanan kepada teman seprofesinya untuk terus menanamkan nilai kejujuran baik untuk dirinya maupun untuk peserta didiknya melalui mata pelajaran yang diampu.

Tentunya dalam membentuk kejujuran siswa, hal tersebut tidak mudah dilakukan, namun hingga saat ini sikap jujur yang dimiliki siswa SMA Angkasa diakui secara jelas oleh guru-guru SMA Angkasa Adisutjipto Yogyakarta seperti pernyataan dari salah satu guru tersebut. Ibu SR mengatakan bahwa kejujuran merupakan bagian dari kedisiplinan dan hal itu 
terbentuk karena adanya peran dari TNI AU. Dengan demikian bangunan akademik yang mengedepankan nilai-nilai kejujuran akan menjadi sebuah kebanggaa tersendiri, peserta didik bangga kepada lembaga sekolah dan tenaga pendidiknya, guru bangga kepada peserta didik dan lembaganya.

Nilai keteladanan dan ketertiban diajarkan berdasarkan praktek yang diberikan oleh guru dan TNI AURI Adisutjipto telah berhasil ditanamkan pada karakter siswa, keteladanan yang berupa hadir sebelum bel berlangsung, menggunakan seragam dan sepatu sesuai ketentuan yang berlaku serta contoh lainnya, sehingga memudahkan siswa untuk mematuhi menerapkan dan mematuhi aturan yang ada karena memiliki contoh dalam melaksanakan aturan maupun tata tertib yang berlaku di sekolah. Selain itu tata tertib dibuat untuk meminimalisir perilaku menyimpang berdasarkan musyawarah yang dilakukan antara pihak sekolah dengan orangtua siswa. perilaku yang tumbuh dan berkembang di sekolah adalah guru yang penuh disiplin dalam melaksanakan tugas, ketertiban yang ditentukan berdasarkan kesepakatan dan musyawarah pihak sekolah dengan orangtua siswa, peraturan tersebut sangat dijunjung tinggi, sehingga siswa dalam kondisi disiplin dan tata tertib yang selalu terjaga.

Siswa SMA Angkasa Adisutjipto Yogyakarta juga memiliki rasa kepedulian yang tinggi. Hal ini ditinjau dari sikap toleransi siswa dan kepedulian terhadap lingkungan sekolah. Pada prakteknya terlihat dari perilaku siswa yang membuang sampah pada tempat yang disediakan, membantu sesama dalam kesulitan, memiliki partisipasi yang tinggi untuk mengikuti upacara/apel maupun event yang diadakan oleh sekolah serta memahami perbedaan ras dan agama tanpa membedakan satu sama lainnya, dengan begitu terlihat jelas bahwa SMA Angkasa berusaha mempertahankan kultur sekolah yang baik dan positif dengan komitmen dan konsistensi yang berdasarkan dukungan dari seluruh warga sekolah.

\section{Simpulan}

Berdasarkan penelitian yang dilakukan di SMA Angkasa Adisutjipto Yogyakarta, maka dapat ditarik kesimpulan bahwa SMA Angkasa Adisutjipto memperlihatkan kultur sekolah yang baik yaitu dengan mengutamakan kedisiplinan yang di wujudkan dalam pembentukan visi sekolah "Disiplin, Bermutu, Peduli, dan Budaya lingkungan berdasarkan iman dan taqwa" dengan begitu dalam mendisiplinkan siswa diperlukan penguatan karakter siswa. Penguatan karakter tersebut berupa penguatan lingkungan, pembiasaan, dan pengajaran.

Siswa di SMA Angkasa dididik langsung oleh TNI AU. Setiap pagi mulai pukul 5.30 petugas TNI AU dan guru-guru berada di depan gerbang untuk saling bersalaman sekaligus kehadiran siswa serta kesiapan siswa untuk melaksanakan 
kegiatan apel pagi yang setiap hari dilaksanakan selam 5 hari sekolah. Kegiatan Tenaga Pendidik dari TNI AU setiap hari nya adalah untuk melatih kedisiplinan siswa terhadap tata tertib yang berlaku dan mengecek penampilan siswa yang harus terlihat rapi dan bersih dengan atribut yang lengkap, Bagi siswa yang melakukan pelanggaran akan diberikan sanksi sesuai dengan perintah dan hukuman yang diberikan oleh TNI AU.

Dari segi artifak, kondisi lingkungan SMA Angkasa, sangat mendukung dalam proses pembentukan kedisiplinan, karena sekolah berada di kawasan landasan udara adisutjipto sehingga siswa akan kesulitan untuk keluar dari sekolah saat jam pelajaran dan hubungan antar warga sekolah terlihat harmonis karena kesadaran untuk saling toleran yang terlihat dari penerapan $3 \mathrm{~S}$ (senyum, salam dan sapa) wajib diterapkan di kawasan SMA Angkasa, baik antar siswa kepada guru, siswa kepada TNI AU maupun siswa kepada kakak kelas serta diwajibkan mengenakan Seragam dan sepatu sesuai kriteria yang ditentukan oleh sekolah, sehingga jika terdapat siswa yang melakukan pelanggaran maka akan diberikan sanksi fisik berdasarkan dengan hukuman yang diberikan oleh militer Petugas TNI AU

Nilai-nilai yang diyakini oleh warga SMA Angkasa adalah nilai kejujuran, keteladanan, kedisiplinan ataupun ketertiban yang terlihat dari hasil penelitian berdasarkan (1) rasa bangga terhadap sekolah, (2) Perwujudan visi dan misi sekolah, (3) Penghargaan sekolah atas prestasi warga sekolah, (4) Kompetisi siswa dalam meraih prestasi (4) penerapan slogan-slogan yang ada disekolah (5) Penerapan nilai yang ada disekolah. Untuk mempertahankan budaya sekolah diperlukan komitmen dan konsistensi dari seluruh warga sekolah agar mutu dan citra sekolah dapat berkembang dan bertahan serta menjadi lebih baik.

\section{Ucapan Terima kasih}

Terimakasih disampaikan kepada semua pihak yang telah mendukung dalam penulisan ini sehingga terlaksana dengan baik dan tim redaksi Jurnal Dimensia yang telah mempublikasikan hasil karya tulisan ini.

\section{Daftar Pustaka}

Aman, A. Sudrajat, A. \& Yuliana, L. (2018). Effectiveness of social problem solving model in improving social skills of transvestites in the special regions Yogyakarta. Journal of Social Studies (JSS), 14(1). 1-12. Effectiveness of social problem solving model in improving social skills of transvestites in the special regions Yogyakarta

Astuti Dwi, Albertin. (2015). Pengaruh Budaya Sekolah Terhadap Karakter Siswa di SMA 3 Klaten. Jurnal Ilmiah Pendidikan. Yogyakarta: Universitas Negeri Yogyakarta.

Benaziria, B., \& Murdiono, M. (2019). Civic teacher strategy in the integration of nationalism and tolerance character in school based on pesantren in Yogyakarta city. Journal of Social Studies (JSS), 15(1). 13-34. https://doi.org/10.21831/jss.v15i1.2 5227. 
Damsar. (2011). Pengantar Sosiologi Pendidikan. Jakarta: Kencana Prenada Media Group.

Efianingrum, A. (2013). Kultur Sekolah. Jurnal Pemikiran Sosiologi. Volume 2 No. 1, 2013. URL : https://jurnal.ugm.ac.id/jps/article/vi ew/23404/pdf.

Febriyanti, R. (2015). Perilaku Kedisiplinan Siswa Kelas $X$ Selama Proses Pembelajaran IImu Gizi Di SMK N 3 Wonosari. Yogyakarta: Universitas Negeri Yogyakarta.

Hanum, F. (2013). Sosiologi Pendidikan. Yogyakarta: Kanwa Publisher.

Herdiansyah, H. (2010). Metode Penelitian Kualitatif untuk IImu-IImu Sosial. Jakarta: Salemba Humanika.

Ibrahim. (2015). Metodologi Penelitian Kualitatif Panduan Penelitian Beserta Contoh Proposal Kualitatif. Pontianak: Perpustakaan Nasional.

Idrus, M. (2009). Metode Penelitian IImu Sosial Pendekatan Kualitatif dan Kuantitatif Edisi Kedua. Jakarta: Erlangga.

Kharis, A., Sudharto, \& Yuliejantiningsih, Y. (2016). Pengaruh Budaya Sekolah dan Motivasi Berprestasi Terhadap Mutu Sekolah Dasar Negeri di UPTD Pendidikan Kecamatan Kabupaten Brebes. Journal UPGRIS.

Kurniawan, F. (2017). Analisis Penerapan Budaya Sekolah dalam Pembentukan Karakter Disiplin Siswa di Kelas III SD N 2 Blunyahan. Jurnal Pendidikan Guru Sekolah Dasar, Fakultas IImu Pendidikan Universitas Negeri Yogyakarta

Kurniawati, A. (2016). Pengaruh Iklim dan Budaya Sekolah Terhadap Sikap Disiplin Siswa SMP Negeri 3 Terbanggi Besar Tahun Pelajaran 2015/2016. Bandar Lampung: Universitas Lampung. Journal Kultur Demokrasi.

Martono, N. (2014). Sosiologi Pendidikan Michel Foucalt: Pengetahuan, Kekuasaan, Disiplin, Hukuma, dan Seksualitas. Jakarta: Rajawali Pers.

Maulina, I. (2017). Kultur Akademik di Sekolah Menengah Atas Taruna Nusantara Magelang. Yogyakarta: Universitas Negeri Yogyakarta.
Nasution. (2014). Sosiologi Pendidikan. Jakarta: Bumi Aksara.

Ningsih, I. R. (2015). Peran Kultur Sekolah Dalam Meminimalisasi Kenakalan Remaja Di Man Yogyakarta III. Yogyakarta: Universitas Negeri Yogyakarta.

Ngila, Winnie Muthoni. (2017). Student Emotional Intelligence and Self Discipline in Secondary Schools in Kenya. Journal of Research Innovation and Implications in Education (JRIIE) Vol. 1(3) pp. 82 95, June 2017. Online ISSN: 25207504

URL http://jriie.com/index.php/JRIIE/inde $\mathrm{x}$

Sari, P. N. (2017). Pengembangan Karakter Siswa Melalui Budaya Sekolah yang Religius di SD Aisiyah Unggulan Gomolong Tahun 2017. Jurnal Pendidikan, 2.

Sugiyono. (2015). Metode Penelitian Kualitatif, Kuantitatif dan Kombinasi (Mixed Methods). Bandung: Alfabeta.

Trisnawati, D. D. (2013). Membangun Disiplin dan Tanggung Jawab Siswa SMA Khadijah Surabaya melalui Implementasi Tata Tertib Sekolah. Kajian Moral dan Kewarganegaraan Nomor 1 Volume 2 Tahun 2013.

Tuloli, J., \& Ismail, D. E. (2016). Pendidikan Karakter. Yogyakarta: UII Press Yogyakarta.

Zamroni. (2013). Manajemen Pendidikan suatu Usaha Meningkatkan Mutu Sekolah. Yogyakarta: Penerbit Ombak.

Ohlson, Matthew; Swanson, Anne ; Adams, Andrea ; Byrd, Anna. (2016). A Culture of Success-Examining School Culture and Student Outcomes via a Performance Framework. Journal of Education and Learning; Vol. 5, No. 1; 2016 ISSN 1927-5250 E-ISSN 19275269 Published by Canadian Center of Science and Education. URL: http://dx.doi.org/10.5539/jel.v5n1p1 14

Maslowski, Ralf. (2015). School Culture and School Performance. Journal of Educational Administration. 
URL:

https://www.researchgate.net/publi

SEKOLAH\&hl=id\&as_sdt=0,5 cation $/ 235300819$

Ehiane, O. Stanley. (2014). Discipline and Academic Performance (A Study of Selected secondary Schools in Lagos, Nigeria. International Journal of Academic Research in Progressive Education and Development. January 2014, Vol. 3, No. 1 ISSN: 2226-6348.

URL:

http://dx.doi.org/10.6007/IJARPED/ v3-i1/758

Kurniawan, Farida. (2010). Analisis Penerapan Budaya Sekolah Dalam Pembentukan Karakter Disiplin Siswa Di Kelas lii Sd N 2 Blunyahan. Yogyakarta: Pendidikan Guru Sekolah Dasar, Fakultas IImu Pendidikan Universitas Negeri Yogyakarta.

URL:http://faridakurniawan.blogs.u ny.ac.id/wp-

content/uploads/sites/15485/2017/1

O/ANALISIS-PENERAPAN-

BUDAYA-SEKOLAH-DALAM-

PEMBENTUKAN-KARAKTER-

DISIPLIN-SISWA-DI-KELAS-III-SDN-2-BLUNYAHAN.pdf

Sari, N. W., \& Hanum, M.Si, P. F. (2017).

Peran Kultur Sekolah Dalam Membangun Prestasi Siswa Di MAN 1 Yogyakarta . Journal Pendidikan Sosiologi.

URL:

https://eprints.uny.ac.id/53139/6/JU RNAL\%2013413241013.pdf

Susilo, J.M. (2016). Strategi Menciptakan Budaya Sekolah Yang Kondusif Melalui Paradigma Sekolah Unggul Muhammadiyah. Yogyakarta: Jurnal Prosiding Symbion (Symposium on Biology Education) URL:https://scholar.google.co.id/sc holar?q=related:zixIRBp55awJ:sch ola.google.com/\&scioq=ARTEFAK+ 